\title{
The role of peroxisome proliferator-activated receptor in the treatment of non-alcoholic fatty liver disease
}

XIN SUN ${ }^{1}$

YAN ZHANG ${ }^{2,3^{*}}$

MEILIN XIE ${ }^{3 *}$

${ }^{1}$ Department of Pharmacy

Wuxi No. 2 People's Hospital

The Affiliated Hospital of Nanjing

Medical University, Wuxi, Jiangsu

214002, China

${ }^{2}$ Department of Gynecology and Obstetrics, Wuxi Maternal and Child

Health Hospital, The Affiliated Hospital of Nanjing Medical University, Wuxi Jiangsu, 214002, China

${ }^{3}$ Department of Pharmacology

College of Pharmaceutical Sciences

Soochow University, Suzhou, Jiangsu

215123, China

\begin{abstract}
Non-alcoholic fatty liver disease (NAFLD) has been defined as a spectrum of histological abnormalities and is characterized by significant and excessive accumulation of triglycerides in the hepatocytes in patients without alcohol consumption or other diseases. Current studies are targeting new molecular mechanisms that underlie NAFLD and associated metabolic disorders. Many therapeutic targets have been found and used in clinical studies. Peroxisome proliferator-activated receptors (PPARs) are among the potential targets and have been demonstrated to exert a pivotal role in modulation of NAFLD. Many drugs developed so far are targeted at PPARs. Thus, the aim of this paper is to summarize the roles of PPARs in the treatment of NAFLD.
\end{abstract}

Keywords: non-alcoholic fatty liver disease, peroxisome proliferator-activated receptors, agonists, insulin resistance, inflammation

Non-alcoholic fatty liver disease (NAFLD) is the commonest cause of liver disease in humans. Its main characteristic is excessive accumulation of triglycerides in the hepatocytes without consumption of alcohol or other drugs (1). NAFLD includes a wide variety of conditions, from simple steatosis to non-alcoholic steatohepatitis (NASH) and can eventually lead to cirrhosis, liver failure, and/or hepatocellular carcinoma $(2,3)$. According to the literature, about $10-29 \%$ of NASH patients might progress to liver cirrhosis within 10 years and about $4-27 \%$ of liver cirrhosis patients might develop hepatocellular carcinoma (HCC) (Fig. 1) (4,5). The diagnosis of NAFLD remains unclear because many patients are asymptomatic until late stages of the disease. In clinics, liver biopsy is recognized as the

\footnotetext{
*Correspondence; yaoxue2030@163.com, xiemeilin@suda.edu.cn
} 


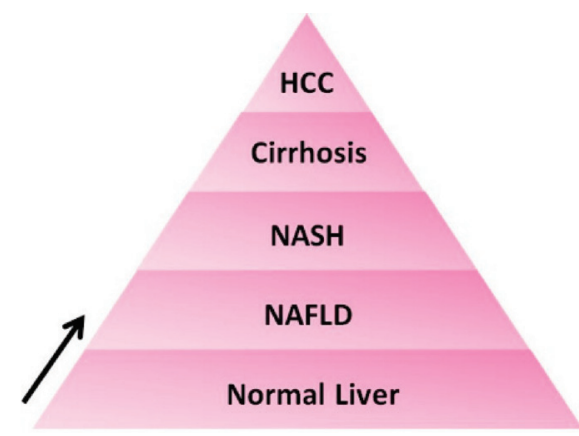

Fig. 1. Natural history of nonalcoholic fatty liver disease. NAFLD - nonalcoholic fatty liver disease, NASH - non-alcoholic steatohepatitis, HCC - hepatocellular carcinoma.

major and also the most accurate tool to diagnose NAFLD. However, liver biopsy often carries a serious risk of complications (6). Hence, more research is needed to discover new drugs.

\section{PATHOGENESIS OF NAFLD}

The natural history and pathogenesis of NAFLD are still poorly understood. The key factors in the progress of NAFLD are still not clearly defined. In recent years, many literature sources have reported the pathogenesis of NAFLD, mainly including two-hit (Fig. 2, red frame) (7), and multiple parallel hit (Fig. 2, blue frame) $(8,9)$ hypotheses.

The first hit is the development of hepatic steatosis while the second hit includes cellular stresses such as oxidative stress, apoptosis stress and gut-derived lipopolysaccharide stress (LPS). In these two hypotheses, insulin resistance is regarded as the most important

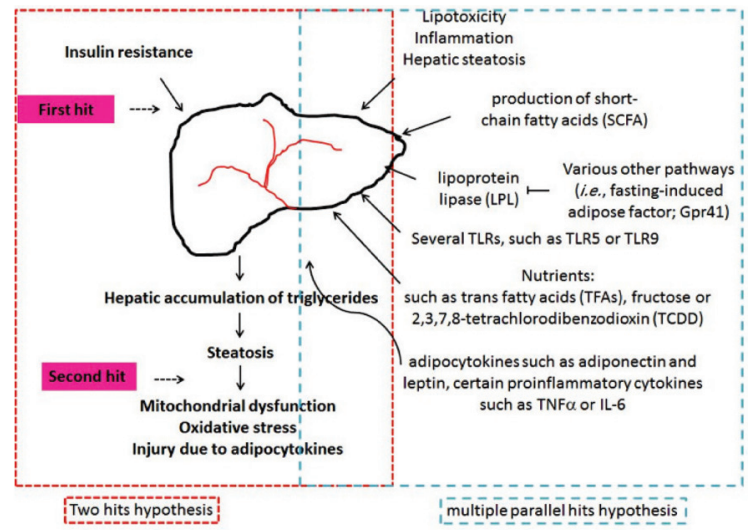

Fig. 2. The two hits hypothesis and the multiple parallel hits hypothesis. 
factor. In the two-hits hypothesis, hepatic steatosis develops after a first hit and progresses to NAFLD by a subsequent hit including cellular stresses (such as oxidative stress, gut-derived lipopolysaccharide stress, etc.). Although fatty liver is usually non-progressive, it can progress in patients harboring the risk allele of many genes that play an important role in the development of NASH, such as patatin-like phospholipase 3 (PNPLA3) (10). Thus, the development of NAFLD is regarded a multiple hit process.

In the parallel hits hypothesis, there are multiple parallel hits, such as fasting-induced adipose factor, adipocytokines, certain proinflammatory cytokines, etc. (see details in Fig. 2). Hepatic steatosis occurs due to the imbalance between triglyceride accumulation and elimination in the liver. Insulin resistance (IR) is closely and frequently related to the development of NAFLD because it can alter nutrient metabolism (11). Hepatic inflammation is caused by the increase of many inflammatory cytokines, such as interleukin 6 (IL6), tumor necrosis factor $\mathrm{TNF} \alpha$, etc. It can be also caused by a decrease of many anti-inflammatory cytokines, such as adiponectin (12).

\section{PEROXISOME PROLIFERATOR-ACTIVATED RECEPTOR}

There are many important regulators among the main discovered mechanisms. Peroxisome proliferator-activated receptor (PPAR) is one of these factors. PPARs are associated with nutrient metabolism and cellular proliferation. There are four subtypes in the PPAR family, namely, PPAR $\alpha, \operatorname{PPAR} \beta, \operatorname{PPAR} \gamma$ and PPAR $\delta$. PPAR $\alpha(\mathrm{NR} 1 C 1)$ is highly expressed in the tissues with high fatty acid oxidation such as liver (13). PPAR $\beta / \delta$ (NR1C2) is highly expressed in liver, cardiac, kidney and skeletal muscles, brain, adipose tissues, colon and vasculature (14). PPAR $\gamma$ (NR1C3) is highly expressed in adipose tissues (15). PPAR $\gamma$ plays an important role in the transcription process, glucose metabolisms and other events (16).

PPARs are nuclear receptors that are parts of the steroid, retinoid, and thyroid hormone receptor superfamily of ligand-activated transcription factors (16, 17). PPAR isoforms have four functional domains, termed A/B domain, DNA-binding domain (DBD), hinge domain (HD) and ligand-binding domain (LBD). Among these domains, the A/B domain contains the activation function (AF)-1 and is ligand-independent. AF-1 plays an important role in the progress of kinase phosphorylation. DBD domain contains two highly conserved zinc finger motifs and promotes the binding of receptors to a DNA sequence in the promoter region of target genes. It is known as the peroxisome proliferator response element (PPRE). The HD domain acts as a docking site used for cofactors. The LBD is responsible for ligand specificity and increases target gene transactivation (18) (see details in Fig. 3).

Due to the important role of PPARs in the treatment of NAFLD, researchers have paid great attention to drug discovery based on PPARs, especially PPAR agonists. As shown below, there are two main mechanisms of PPAR agonists.

\section{PPAR agonists and insulin resistance in NAFLD}

As insulin resistance is the major mechanism in the progression of NAFLD, many researchers and physicians are paying increasing attention to the potential therapeutic effects of insulin sensitizers. Insulin binds with its specific receptor and activates the in- 


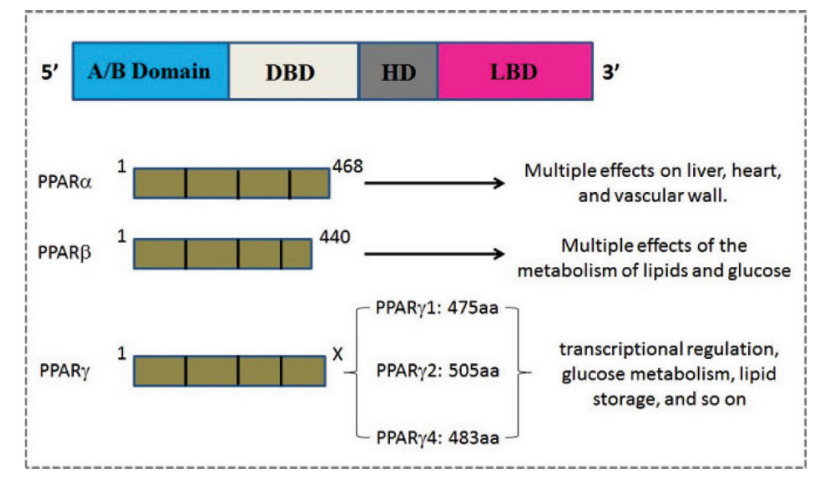

Fig. 3. Schematic structure of peroxisome proliferator-activated receptor (PPARs).

tracellular signaling pathway. Insulin receptor then phosphorylates itself and insulin receptor family members such as IRS1 and IRS2. IRS1 and IRS2 regulate insulin homeostasis by mediating insulin signaling and inducing insulin sensitivity in the liver (19). Insulin resistance (IR) has been demonstrated in many research reports to lead to inflammation and inflammatory response in the progress of NAFLD (20).

Thiazolidinediones (TZDs) contain two heteroatoms, nitrogen and sulfur. They can activate the nuclear transcription factor named peroxisome proliferator-activated receptor gamma (PPAR $\gamma)$. PPAR $\gamma$ can upregulate specific genes that decrease insulin resistance, inflammation, proliferation, etc., and increase insulin sensitivity. Among them, the representatives of TZDs are troglitazone, rosiglitazone and pioglitazone. In addition to being reported as cancer treatment drugs, they have also been approved for the treatment of diabetes mellitus type II (21). Clinically, troglitazone is the first TZD that is widely used in the treatment for diabetes. The first clinical study revealed that seven of ten NASH patients who received troglitazone (400 mg per day for 6 months) normalized alanine aminotransferase (ALT) at the end of the treatment (22).

Ample data have suggested the potential therapeutic effects of TZDs on NAFLD and liver steatosis, presumably due to their action of decreasing insulin resistance, beneficial effects of glucose, etc. $(23,24)$. As far as rosiglitazone and pioglitazone are concerned, many researchers have demonstrated that they show severe side effects, such as cardiovascular morbidity of rosiglitazone and facilitation of bladder cancer of pioglitazone $(24,25)$. According to the PROspective poplitazone (PROactive) clinical trial database, pioglitazone reduced cardiovascular complications compared to the control patients (26).

\section{PPAR agonists and inflammation in NAFLD}

As confirmed by many researchers, along with insulin resistance, inflammation has also been demonstrated to be a key pathway in the development of hepatic diseases such as NAFLD. Hepatic pro-inflammatory cytokines are also regarded as important markers of the increasing severity of liver disease, such as transcription factor NF- $\kappa$, etc. (23). NF- $\kappa \mathrm{B}$ plays a crucial role in the process of inflammation chain, including cellular proliferation, chemokines, etc. (27). Many literature sources have revealed that insulin resistance could 
enhance inflammation in NAFLD/NASH. Also, inflammation could disrupt insulin signaling, for example, serine phosphorylation of insulin receptor substrate by inflammatory signal transducers such as NF- $\kappa$ B inhibitor (27). Interleukin 6 (IL-6) is an interleukin that acts both as a pro-inflammatory cytokine and an anti-inflammatory myokine. In humans, it is encoded by the IL6 gene, a target gene of NF- $\kappa \mathrm{B}$, and its expression was more than 100fold higher in adipose tissue compared to its expression in liver tissue (28). On the other hand, another important inflammatory factor in NAFLD patients is the tumor necrosis factor (TNF- $\alpha$ ). Researchers have demonstrated that the severity of NAFLD might be associated with the increased level of TNF- $\alpha$ in NAFLD patients $(29,30)$. TNF $\alpha$ could bind to trimerized TNF receptor type I and activate NF- $\kappa \mathrm{B}$ via the inhibitor of the nuclear factor kappa-B kinase (IKK) pathway. TNF- $\alpha$ could induce c-Jun N-terminal kinase (JNK) activation, which is associated with the induction of hepatocyte death $(31,32)$. On the other hand, $\mathrm{Lv}$ and his colleagues (33) found that TNF- $\alpha$ could directly induce lipid accumulation through the AMP-activated protein kinase (AMPK) pathway, which is known as an important factor in the process of energy homeostasis. In addition, lipopolysaccharides (LPS) could induce activation of mitogen-activated protein kinases (MAPKs) and liver injury (28).

All studies have clearly revealed that inflammatory factors are important regulators involved in NAFLD/NASH. Hence, suppressing inflammation might be an attractive therapeutic approach for improving inflammatory liver disease and the associated insulin resistance. Recent studies have shown that PPARs could produce anti-inflammatory effects. PPARs could accelerate lipid catabolism, which might reduce liver steatosis. Many experiments have revealed that PPAR agonists could attenuate the symptoms of NAFLD/ NASH (33). Mechanisms of the beneficial metabolic effects of PPAR activation may be the following: (i) insulin resistance associated with pro-inflammatory microenvironment, (ii) effects of the tumor necrosis factor-alpha (TNF $\alpha$ ) in adipocytes, (iii) activation of cytokinemediated signaling (e.g., via NF- $\kappa \mathrm{B}$ ) enhancing insulin action, (iv) reducing circulating levels of proteins that serve as markers of inflammation, $(v)$ inducing the expression of adiponectin implicated as having anti-inflammatory activity (see details in Fig. 4).

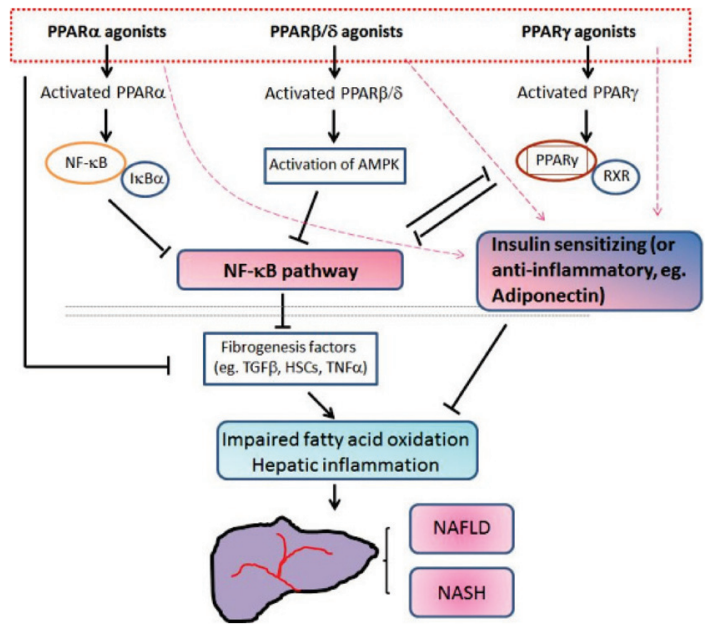

Fig. 4. PPARs regulate the inflammation in the NAFLD. 
Based on the above mentioned important role of PPARs in NAFLD, researchers and clinicians have discovered many PPAR agonists besides the above mentioned ones. Thus, according to the different subtypes of PPARs, we have summarized all the PPAR agonists that have been reported (see Table I).

$\operatorname{PPAR} \alpha$

N-3 polyunsaturated fatty acids (n-3 PUFAs) are PPAR $\alpha$-ligands. PUFA can ameliorate insulin sensitivity through binding PPAR $\alpha$. Patients treated with n-3 PUFA showed reduction of triglyceride and alanine transaminase (ALT) serum levels $(27,34-37)$. Oleoylethanolamine (OEA) has been demonstrated as an endogenous high-affinity PPAR $\alpha$. Researchers have revealed that $5 \mathrm{mg} \mathrm{kg}^{-1}$ per day OEA (i.p.) could ameliorate the development of NAFLD compared to control groups after treatment for 6 weeks through detecting the levels of plasma triglycerides (TG), serum total cholesterol (TC), alanine aminotransferase (ALT) and aspartate transaminase (AST) as well as liver inflammatory cytokines (38).

Another classic agonist of PPAR $\alpha$ is fenofibrate. Fenofibrate could activate lipolytic enzymes, reduce the synthesis of apolipoprotein and remove plasma triglycerides. Fenofibrate is widely used for the treatment of NAFLD. Fenofibrate has been demonstrated to protect against inflammatory injury in NAFLD. The probable mechanism is associated with the endoplasmic reticulum (ER) stress pathway (39). In another report, researchers divided mice into two groups (fructose-fed and fructose-fenofibrate treated groups). The results revealed that after the treatment with $100 \mathrm{mg} \mathrm{kg}^{-1}$ (p.o.), fatty acids (FAs) and very low-density lipoprotein (VLDL), secretions were decreased more than in the control group (40). In a clinical trial, Piyush Patel et al. (41) found that the TG level was reduced in patients who were administered fenofibrate (116 patients were administered choline fenofibrate and 116 patients were administered micronized fenofibrate). Another research group also found that adding pentoxifylline to fenofibrate had a beneficial effect on a direct marker linked to matrix deposition (hyaluronic acid), a cytokine/growth factor linked to liver fibrosis (transforming growth factor beta 1), the inflammatory pathway, insulin resistance and liver stiffness, in non-alcoholic fatty liver patients treated with fenofibrate $(300 \mathrm{mg}$ daily) plus pentoxifylline (1200 $\mathrm{mg}$ per day) for 24 weeks (42).

In some publications, however, researchers reported that fenofibrate exerted side effects, such as nephrotoxicity (leading to renal vasoconstriction) (43) and hepatotoxicity (enhanced the fatty liver mass) (44).

\section{$\operatorname{PPAR} \beta / \delta$}

GW4064 is a PPAR $\beta$ agonist that has highly selective farnesoid X receptor (FXR) affinity. FXR is a member of the nuclear receptor superfamily of ligand activated receptors and is mainly expressed in the liver, intestines, kidneys and adrenal glands. FXR has been found to be a key regulator of lipid metabolism and to improve peripheral insulin sensitivity. Xin et al. (45) found that GW4064 could increase the expression of adiponectin, leptin, adiponectin receptor 2 (AdipoR2) and leptin receptors (OB-Rb).

Chehaibi et al. (46) found that GW0742 is another PPAR $\beta / \delta$ agonist and could upregulate serum HDL-C and HDL phospholipids in NAFLD mice. The effects of GW0742 could be completely abolished in PPAR- $\beta / \delta$-deficient mice (45). GW501516 could prevent endo- 
Table I. PPAR agonists

\begin{tabular}{|c|c|c|c|c|}
\hline Agonist & Drug & Mechanism & Adverse effect(s) & Reference(s) \\
\hline \multirow{5}{*}{ PPAR $\alpha$} & & Single PPAR agonists & \multirow{4}{*}{ Not reported } & \\
\hline & $\begin{array}{l}\text { Oleoylethanol- } \\
\text { amine (OEA) }\end{array}$ & \multirow{4}{*}{$\begin{array}{l}\text { Enhances insulin } \\
\text { sensitivity, reduces } \\
\text { inflammatory injury }\end{array}$} & & 53 \\
\hline & Z-551 & & & 39 \\
\hline & n-3 PUFAs & & & 36 \\
\hline & Fenofibrate & & $\begin{array}{l}\text { Enhances fatty } \\
\text { liver weight } \\
\text { nephrotoxicity }\end{array}$ & 54 \\
\hline & GW4064 & $\begin{array}{c}\text { Farnesoid } \mathrm{X} \text { receptor } \\
\text { agonist, }\end{array}$ & & \\
\hline PPAR $\beta$ & GW0742 & $\begin{array}{l}\text { modulate macrophage } \\
\text { cholesterol efflux }\end{array}$ & Not reported & 44,55 \\
\hline \multirow{4}{*}{$\operatorname{PPAR} \gamma$} & $\begin{array}{l}\text { Thiazolidinedio- } \\
\text { nes (TZDs) }\end{array}$ & \multirow{3}{*}{$\begin{array}{l}\text { Enhance insulin } \\
\text { sensitivity and anti- } \\
\text { inflammatory }\end{array}$} & \multirow{3}{*}{$\begin{array}{l}\text { Fluid retention, } \\
\text { hemodilution } \\
\text { edema, heart } \\
\text { failure }\end{array}$} & \multirow{3}{*}{$45-47$} \\
\hline & Rosiglitazone & & & \\
\hline & Pioglitazone & & & \\
\hline & & Dual PPAR agonists & & \\
\hline $\operatorname{PPAR} \alpha / \delta$ & GFT505 & $\begin{array}{l}\text { Inhibition of hepatic } \\
\text { gluconeogenesis and } \\
\text { anti-inflammatory }\end{array}$ & Not reported & 23,56 \\
\hline $\operatorname{PPAR} \alpha / \gamma$ & $\begin{array}{l}\text { Tesaglitazar } \\
\quad \text { LT175 }\end{array}$ & $\begin{array}{l}\text { Improve insulin } \\
\text { mediated control of } \\
\text { glucose and FFA fluxes }\end{array}$ & Not reported & 52,57 \\
\hline $\operatorname{PPAR} \beta / \delta$ & GW501516 & Anti-inflammatory & Not reported & 58 \\
\hline $\mathrm{PPAR} \gamma / \delta$ & $\begin{array}{c}\text { Alkoxy-3- } \\
\text { indolylacetic acid }\end{array}$ & $\begin{array}{c}\text { Inhibition of the level of } \\
\text { hepatic triglycerides }\end{array}$ & Not reported & 59 \\
\hline
\end{tabular}

plasmic-reticulum (ER) stress associated with inflammation and insulin resistance. The published data showed that the mechanisms might be related to activation of the AMP activated protein kinase (AMPK) pathway and inhibition of the extracellular-signal-regulated kinase (ERK)1/2 pathway (46).

$\operatorname{PPAR} \gamma$

PPAR $\gamma$ plays an indispensable role in adipogenesis, which is frequently impaired under pathological conditions such as nonalcoholic fatty liver disease (NAFLD) or nonalcoholic steatohepatitis (NASH). Many drugs were developed based on the activation of PPAR $\gamma$, such as telmisartan (47), rivoglitazone (48), etc. 
Rivoglitazone is a novel agonist of PPAR $\gamma$ that has been demonstrated in rats and monkeys. It has significant stereoselectivity and is very efficacious. Rivoglitazone could enhance adiponectin levels in plasma and decrease adipose mRNA levels in mice. Rivoglitazone could also ameliorate insulin resistance (49). In clinics, rivoglitazone has been used to treat type 2 diabetes, but rivoglitazone has many adverse effects such as peripheral edema and weight gain (50).

\section{Dual PPAR agonist}

GFT505 is a PPAR agonist with preferential activity on PPAR $\alpha$ with half-maximal effective concentration of about $10-20 \mathrm{nmol} \mathrm{L}^{-1}$ and additional activity on PPAR $\delta$ with halfmaximal effective concentration of about $100-150 \mathrm{nmol} \mathrm{L}^{-1}$. Researchers have found that GFT505 could improve glycemic control in $\mathrm{db} / \mathrm{db}$ mice, which is related to its liver-centric effects on hepatic insulin sensitivity and gluconeogenesis (49). Also, in phase II of clinical studies, researchers found that GFT505 treatment decreased alanine aminotransferase, gamma-glutamyl transpeptidase and alkaline phosphatase (51). Shiomi et al. (36) found that Z-551, having both PPAR $\alpha$ and PPAR $\gamma$ antagonistic activities, could increase the level of molecules involved in fatty acid combustion and thus significantly reduce fasting plasma levels of glucose, triglycerides, free fatty acids, insulin and leptin. This indicated that Z-551 might be clinically useful for preventing or treating metabolic disorders such as type 2 diabetes, dyslipidemia and NAFLD (52).

Zhao et al. (53) found that osthole might be a dual agonist of PPAR $\alpha / \gamma$ and could decrease hepatic lipid accumulation. After treating the rats with $5-20 \mathrm{mg} \mathrm{kg}^{-1}$ osthole for 4 weeks, the results showed that the serum alanine aminotransferase, aspartate aminotransferase, total cholesterol, triglyceride, and free fatty acid levels, tumor necrosis factor- $\alpha$ $(\mathrm{TNF}-\alpha)$ and liver index were lower in the osthole treated group than in the control group. This demonstrated that osthole was effective in treating rat steatohepatitis (36).

\section{CURRENT PROBLEMS}

Although many researchers have revealed the molecular mechanism in the development of NAFLD such as inflammation, the basic and clinical trials are still needed to face additional challenges. Thus far, PPARs have been considered as effective molecular targets that could be used to treat liver disease. However, they also need more clinical evidence before their clinical application. For example, insulin sensitizer might induce some side effects, such as heart attack, heart failure, weight gain, etc. (60). The adverse effects of each PPAR agonist are summarized in Table I. In order to overcome these adverse effects, many researchers found that dual PPAR agonists could improve liver injury without side effects induced by single PPAR agonists (13, 61-63). Clinical trials also demonstrated that PPAR agonist therapies may lead to side effects such as paradoxical dissociation of steatosis, inflammation, etc. Thus, much work still remains to be done to fully cure the NAFLD in order to separate the beneficial effects of PPAR agonists from unwanted side effects.

\section{CONCLUSIONS}

In this review, we focused on and outlined the PPAR agonists in the treatment of NAFLD. Elucidating detailed mechanisms of these drugs could provide new targets for 
future therapeutic strategies in NAFLD. The effect and safety of NAFLD management should be taken into account as well.

In summary, further large-scale clinical trials and practice are needed to verify drug treatments.

Acronyms, abbreviations, symbols. - AdipoR2 - adiponectin receptor 2, ALT - alanine aminotransferase, AMPK - AMP activated protein kinase, AST - aspartate transaminase, DBD - DNA-binding domain, ER - endoplasmic-reticulum, FAs - fatty acids, ERK- extracellular-signal-regulated kinase, FFA - free fatty acid, FXR - farnesoid X receptor, HCC hepatocellular carcinoma, HD - hinge domain, IKK - inhibitor of nuclear factor kappa-B kinase, JNK - c-Jun N-terminal kinase, IL6 - interleukin 6, IR - insulin resistance, LBD ligand-binding domain, LPS - lipopolysaccharide, MAPKs - mitogen-activated protein kinases, n-3 PUFAs - n-3 polyunsaturated fatty acids, NAFLD - non-alcoholic fatty liver disease, NASH - non-alcoholic steato-hepatitis, NF- $\kappa \mathrm{B}$ - nuclear factor $\kappa \mathrm{B}$, OEA - oleoylethanolamine, PNPLA3 - patatin-like phospholipase 3, PPAR $\alpha$ - peroxisome proliferatoractivated receptor alpha, PPAR $\beta$ - peroxisome proliferator-activated receptor beta, PPAR $\delta$ - peroxisome proliferator-activated receptor delta, PPAR $\gamma$ - peroxisome proliferator-activated receptor gamma, PPARs - peroxisome proliferator-activated receptors, TC - total cholesterol, TG - triglyceride, TNF $\alpha$ - tumor necrosis factor alpha, TZDs - thiazolidinediones, VLDL - very low density lipoprotein.

Acknowledgements. - This work was partly supported by the National Natural Science Foundation of China (\#81401222).

\section{REFERENCES}

1. G. Ganzetti, A. Campanati and A. Offidani, Non-alcoholic fatty liver disease and psoriasis: So far, so near, World J. Hepatol. 7 (2015) 315-326; DOI: 10.4254/wjh.v7.i3.315.

2. A. Kotronen and H. Yki-Jarvinen, Fatty liver: a novel component of the metabolic syndrome, Arterioscler. Thromb. Vasc. Biol. 28 (2008) 27-38; DOI: ATVBAHA.107.147538.

3. M. Takeuchi, J. Takino, A. Sakasai-Sakai, T. Takata, T. Ueda, M. Tsutsumi, H. Hyogo and S. Yamagishi, Involvement of the TAGE-RAGE system in non-alcoholic steatohepatitis: Novel treatment strategies, World J. Hepatol. 6 (2014) 880-893; DOI: 10.4254/wjh.v6.i12.880.

4. C. S. Hsu and J. H. Kao, Non-alcoholic fatty liver disease: an emerging liver disease in Taiwan, J. Formos. Med. Assoc. 111 (2012) 527-535; DOI: 10.1016/j.jfma.2012.07.002.

5. A. S. Bodzin and R. W. Busuttil, Hepatocellular carcinoma: Advances in diagnosis, management, and long term outcome, World J. Hepatol. 7 (2015) 1157-1167; DOI: 10.4254/wjh.v7.i9.1157.

6. P. Loria, A. Lonardo, L. Carulli, A. M. Verrone, M. Ricchi, S. Lombardini, A. Rudilosso, S. Ballestri and N. Carulli, Review article: the metabolic syndrome and non-alcoholic fatty liver disease, Aliment. Pharmacol. Ther. 22 (Suppl 2) (2005) 31-36; DOI: APT2592.

7. D. Papandreou and E. Andreou, Role of diet on non-alcoholic fatty liver disease: An updated narrative review, World J. Hepatol. 7 (2015) 575-582; DOI: 10.4254/wjh.v7.i3.575.

8. C. P. Day and O. F. James, Steatohepatitis: a tale of two "hits"?, Gastroenterology 114 (1998) 842-845; DOI: S0016508598003564.

9. P. Angulo, Nonalcoholic fatty liver disease, N. Engl. J. Med. 346 (2002) 1221-1231; DOI: 10.1056/ NEJMra011775.

10. A. Takaki, D. Kawai and K. Yamamoto, Multiple hits, including oxidative stress, as pathogenesis and treatment target in non-alcoholic steatohepatitis (NASH), Int. J. Mol. Sci. 14 (2013) 20704-20728; DOI: 10.3390/ijms141020704. 
11. H. Tilg and A. R. Moschen, Evolution of inflammation in nonalcoholic fatty liver disease: the multiple parallel hits hypothesis, Hepatology 52 (2010) 1836-1846; DOI: 10.1002/hep.24001.

12. W. Tomeno, M. Yoneda, K. Imajo, Y. Ogawa, T. Kessoku, S. Saito, Y. Eguchi and A. Nakajima, Emerging drugs for non-alcoholic steatohepatitis, Expert Opin. Emerg. Drugs 18 (2013) 279-290; DOI: 10.1517/14728214.2013.811232.

13. Y. Takahashi, K. Sugimoto, H. Inui and T. Fukusato, Current pharmacological therapies for nonalcoholic fatty liver disease/nonalcoholic steatohepatitis, World J. Gastroenterol. 21 (2015) 3777-3785; DOI: 10.3748/wjg.v21.i13.3777.

14. S. R. Pyper, N. Viswakarma, S. Yu and J. K. Reddy, PPARalpha: energy combustion, hypolipidemia, inflammation and cancer, Nucl. Recept. Signal. 8 (2010) e002; DOI: 10.1621/nrs.08002.

15. K. S. Kilgore and A. N. Billin, PPARbeta/delta ligands as modulators of the inflammatory response, Curr. Opin. Invest. Drugs 9 (2008) 463-469.

16. S. J. Bensinger and P. Tontonoz, Integration of metabolism and inflammation by lipid-activated nuclear receptors, Nature 454 (2008) 470-477; DOI: 10.1038/nature07202.

17. L. Zeng, W. J. Tang, J. J. Yin and B. J. Zhou, Signal transductions and nonalcoholic fatty liver: a mini-review, Int. J. Clin. Exp. Med. 7 (2014) 1624-1631.

18. L. Michalik, J. Auwerx, J. P. Berger, V. K. Chatterjee, C. K. Glass, F. J. Gonzalez, P. A. Grimaldi, T. Kadowaki, M. A. Lazar, S. O’Rahilly, C. N. A. Palmer, J. Plutzky, J. K. Reddy, B. M. Spiegelman, B. Staels and W. Wahli, International Union of Pharmacology. LXI. Peroxisome proliferator-activated receptors, Pharmacol. Rev. 58 (2006) 726-741; DOI: 10.1124/pr.58.4.5 58/4/726 [pii ].

19. D. Usuda and T. Kanda, Peroxisome proliferator-activated receptors for hypertension, World J. Cardiol. 6 (2014) 744-754; DOI: 10.4330/wjc.v6.i8.744.

20. V. T. Samuel and G. I. Shulman, Mechanisms for insulin resistance: common threads and missing links, Cell 148 (2012) 852-871; DOI: 10.1016/j.cell.2012.02.017.

21. F. Kim, M. Pham, E. Maloney, N. O. Rizzo, G. J. Morton, B. E. Wisse, E. A. Kirk, A. Chait and M. W. Schwartz, Vascular inflammation, insulin resistance, and reduced nitric oxide production precede the onset of peripheral insulin resistance, Arterioscler. Thromb. Vasc. Biol. 28 (2008) 1982-1988; DOI: 10.1161/ATVBAHA.108.169722.

22. S. H. Caldwell, E. E. Hespenheide, J. A. Redick, J. C. Iezzoni, E. H. Battle and B. L. Sheppard, A pilot study of a thiazolidinedione, troglitazone, in nonalcoholic steatohepatitis, Am. J. Gastroenterol. 96 (2001) 519-525; DOI: S0002-9270(00)02346-7.

23. E. Frohlich and R. Wahl, Chemotherapy and chemoprevention by thiazolidinediones, Biomed. Res. Int. 2015 (2015) Article ID 845340; DOI: 10.1155/2015/845340.

24. H. B. Bhatt and R. J. Smith, Fatty liver disease in diabetes mellitus, Hepatobil. Surg. Nutr. 4 (2015) 101-108; DOI: 10.3978/j.issn.2304-3881.2015.01.03.

25. M. O. Rakoski, A. G. Singal, M. A. Rogers and H. Conjeevaram, Meta-analysis: insulin sensitizers for the treatment of non-alcoholic steatohepatitis, Aliment. Pharmacol. Ther. 32 (2010) 1211-1221; DOI: 10.1111/j.1365-2036.2010.04467.x.

26. A. S. Laganá, S. G. Vitale, A. Nigro, V. Sofo, F. M. Salmeri, P. Rossetti, A. M. C. Rapisarda, S. La Vignera, R. A. Condorelli, G. Rizzo and M. Buscema, Pleiotropic Actions of peroxisome proliferator-activated receptors (PPARs) in dysregulated metabolic homeostasis, inflammation and cancer: Current evidence and future perspectives, Int. J. Mol. Sci. 17 (2016) Article ID 999 (10 pp); DOI: 10.3390/ijms17070999.

27. C. Ning, L. Liu, G. Lv, Y. Yang, Y. Zhang, R. Yu, Y. Wang and J. Zhu, Lipid metabolism and inflammation modulated by vitamin D in liver of diabetic rats, Lipids Health Dis. 14 (2015) Article ID 31 (9 pages); DOI: 10.1186/s12944-015-0030-5.

28. G. Sabio, M. Das, A. Mora, Z. Zhang, J. Y. Jun, H. J. Ko, T. Barrett, J. K. Kim and R. J. Davis, A stress signaling pathway in adipose tissue regulates hepatic insulin resistance, Science 322 (2008) 1539_ 1543; DOI: 10.1126/science.1160794. 
29. J. H. Peng, T. Cui, Z. L. Sun, F. Huang, L. Chen, L. Xu, Q. Feng and Y. Y. Hu, Effects of Puerariae radix extract on endotoxin receptors and TNF-alpha expression induced by gut-derived endotoxin in chronic alcoholic liver injury, Evid. Based Complement. Alternat. Med. 2012 (2012) Article ID 234987; DOI: 10.1155/2012/234987.

30. Y. Ma, M. Gao, H. Sun and D. Liu, Interleukin-6 gene transfer reverses body weight gain and fatty liver in obese mice, Biochim. Biophys. Acta 1852 (2015) 1001-1011; DOI: 10.1016/j.bbadis.2015.01.017.

31. G. Paredes-Turrubiarte, A. González-Chavez, R. Pérez-Tamayo, B. Y. Salazar-Vázquez, V. S. Hernández, N. Garibay-Nieto, J. M. Fragoso and G. Escobedo, Severity of non-alcoholic fatty liver disease is associated with high systemic levels of tumor necrosis factor alpha and low serum interleukin 10 in morbidly obese patients, Clin. Exp. Med. 16 (2016) 193-201; DOI: 10.1007/s10238-015-0347-4.

32. X. Lin, Z. Zhang, J. M. Chen, Y. Y. Xu, H. R. Ye, J. Cui, Y. Fang, Y. Jin, D. R. Zhu and L. Yuan, Role of APN and TNF-alpha in type 2 diabetes mellitus complicated by nonalcoholic fatty liver disease, Genet. Mol. Res. 14 (2015) 2940-2946; DOI: 10.4238/2015.April.10.1.

33. Q. Lv, Q. Zhen, L. Liu, R. Gao, S. Yang, H. Zhou, R. Goswami and Q. Li, AMP-kinase pathway is involved in tumor necrosis factor alpha-induced lipid accumulation in human hepatoma cells, Life Sci. 131 (2015) 23-29; DOI: 10.1016/j.lfs.2015.03.003.

34. C. Wang, G. Zhou and Z. Zeng, Effects of peroxisome proliferator-activated receptor-beta/delta on sepsis induced acute lung injury, Chin. Med. J. 127 (2014) 2129-2137.

35. L. M. Jiménez-Flores, S. López-Briones, M. H. Macías-Cervantes, J. Ramírez-Emiliano and V. Pérez-Vázquez, A PPAR $\gamma, \mathrm{NF}-\kappa \mathrm{B}$ and AMPK-dependent mechanism may be involved in the beneficial effects of curcumin in the diabetic db/db mice liver, Molecules 19 (2014) 8289-8302; DOI: 10.3390/molecules19068289.

36. Y. Shiomi, T. Yamauchi, M. Iwabu, M. Okada-Iwabu, R. Nakayama, Y. Orikawa, Y. Yoshioka, K. Tanaka, K. Ueki and T. Kadowaki, A novel peroxisome proliferator-activated receptor (PPAR)alpha agonist and PPARgamma antagonist, Z-551, ameliorates high-fat diet-induced obesity and metabolic disorders in mice, J. Biol. Chem. 290 (2015) Article ID 14567-81; DOI: jbc.M114.622191.

37. K. L. Lannan, J. Sahler, N. Kim, S. L. Spinelli, S. B. Maggirwar, O. Garraud, F. Cognasse, N. Blumberg and R. P. Phipps, Breaking the mold: transcription factors in the anucleate platelet and platelet-derived microparticles, Front. Immunol. 6 (2015) Article ID 48; DOI: 10.3389/fimmu.2015.00048.

38. M. Capanni, F. Calella, M. R. Biagini, S. Genise, L. Raimondi, G. Bedogni, G. Svegliati-Baroni, F. Sofi, S. Milani, R. Abbate, C. Surrenti and A. Casini, Prolonged n-3 polyunsaturated fatty acid supplementation ameliorates hepatic steatosis in patients with non-alcoholic fatty liver disease: a pilot study, Aliment. Pharmacol. Ther. 23 (2006) 1143-1151; DOI: 10.1111/j.1365-2036.2006.02885.x.

39. L. Li, L. Chen, X. Lin, Y. Xu, J. Ren, J. Fu and Y. Qiu, Effect of oleoylethanolamide on diet-induced nonalcoholic fatty liver in rats, J. Pharmacol. Sci. 127 (2015) 244-250; DOI: 10.1016/j.jphs.2014.12.001.

40. N. Zhang, Y. Lu, X. Shen, Y. Bao, J. Cheng, L. Chen, B. Li and Q. Zhang, Fenofibrate treatment attenuated chronic endoplasmic reticulum stress in the liver of nonalcoholic fatty liver disease mice, Pharmacology 95 (2015) 173-180; DOI: 10.1159/000380952.

41. P. Patel and H. Barkate, Comparison of efficacy and safety of choline fenofibrate (fenofibric acid) to micronized fenofibrate in patients of mixed dyslipidemia: A randomized, open-label, multicenter clinical trial in Indian population, Indian J. Endocrinol. Metab. 20 (2016) 67-71; DOI: 10.4103/2230-8210.172243.

42. S. M. El-Haggar and T. M. Mostafa, Comparative clinical study between the effect of fenofibrate alone and its combination with pentoxifylline on biochemical parameters and liver stiffness in patients with non-alcoholic fatty liver disease, Hepatol. Int. 9 (2015) 471-479; DOI: 10.1007/s12072015-9633-1.

43. T. Kopf, H. L. Schaefer, M. Troetzmueller, H. Koefeler, M. Broenstrup, T. Konovalova and G. Schmitz, Influence of fenofibrate treatment on triacylglycerides, diacylglycerides and fatty acids in fructose fed rats, PLOS ONE 9 (2014) e106849; DOI: 10.1371/journal.pone.0106849. 
44. R. L. Attridge, C. R. Frei, L. Ryan, J. Koeller and W. D. Linn, Fenofibrate-associated nephrotoxicity: a review of current evidence, Am. J. Health Syst. Pharm. 70 (2013) 1219-1225; DOI: 10.2146/ajhp120131.

45. X. M. Xin, M. X. Zhong, G. L. Yang, Y. Peng, Y. L. Zhang and W. Zhu, GW4064, a farnesoid X receptor agonist, upregulates adipokine expression in preadipocytes and HepG2 cells, World J. Gastroenterol. 20 (2014) 15727-15735; DOI: 10.3748/wjg.v20.i42.15727.

46. K. Chehaibi, L. Cedo, J. Metso, X. Palomer, D. Santos, H. Quesada, M. Naceur Slimane, W. Wahli, J. Julve, M. Vazquez-Carrera, M. Jauhiainen, F. Blanco-Vaca and J. C. Escola-Gil, PPAR-beta/delta activation promotes phospholipid transfer protein expression, Biochem. Pharmacol. 94 (2015) 101108; DOI: 10.1016/j.bcp.2015.01.016.

47. L. Salvado, E. Barroso, A. M. Gomez-Foix, X. Palomer, L. Michalik, W. Wahli and M. VazquezCarrera, PPARbeta/delta prevents endoplasmic reticulum stress-associated inflammation and insulin resistance in skeletal muscle cells through an AMPK-dependent mechanism, Diabetologia 57 (2014) 2126-2135; DOI: 10.1007/s00125-014-3331-8.

48. Y. M. Attia, E. F. Elalkamy, O. A. Hammam, S. S. Mahmoud and A. S. El-Khatib, Telmisartan, an AT1 receptor blocker and a PPAR gamma activator, alleviates liver fibrosis induced experimentally by Schistosoma mansoni infection, Parasit. Vectors 6 (2013) Article ID 199; DOI: 10.1186/17563305-6-199.

49. T. Izumi, F. Tsuruta, T. Ishizuka, K. Nakamura, M. Kothuma and M. Takahashi, Stereoselectivity in pharmacokinetics of rivoglitazone, a novel peroxisome proliferator-activated receptor gamma agonist, in rats and monkeys: model-based pharmacokinetic analysis and in vitro-in vivo extrapolation approach, J. Pharm. Sci. 102 (2013) 3174-3188; DOI: 10.1002/jps.23586.

50. R. L. Koffarnus, K. A. Wargo and H. M. Phillippe, Rivoglitazone: a new thiazolidinedione for the treatment of type 2 diabetes mellitus, Ann. Pharmacother. 47 (2013) 877-885; DOI: 10.1345/aph.1R754.

51. B. Staels, A. Rubenstrunk, B. Noel, G. Rigou, P. Delataille, L. J. Millatt, M. Baron, A. Lucas, A. Tailleux, D. W. Hum, V. Ratziu, B. Cariou and R. Hanf, Hepatoprotective effects of the dual peroxisome proliferator-activated receptor alpha/delta agonist, GFT505, in rodent models of nonalcoholic fatty liver disease/nonalcoholic steatohepatitis, Hepatology 58 (2013) 1941-1952; DOI: 10.1002/ hep. 26461.

52. R. Hanf, L. J. Millatt, B. Cariou, B. Noel, G. Rigou, P. Delataille, V. Daix, D. W. Hum and B. Staels, The dual peroxisome proliferator-activated receptor alpha/delta agonist GFT505 exerts anti-diabetic effects in $\mathrm{db} / \mathrm{db}$ mice without peroxisome proliferator-activated receptor gamma-associated adverse cardiac effects, Diab. Vasc. Dis. Res. 11 (2014) 440-447; DOI: 10.1177/1479164114548027.

53. X. Zhao, J. Xue, X. L. Wang, Y. Zhang, M. Deng and M. L. Xie, Involvement of hepatic peroxisome proliferator-activated receptor alpha/gamma in the therapeutic effect of osthole on high-fat and high-sucrose-induced steatohepatitis in rats, Int. Immunopharmacol. 22 (2014) 176-181; DOI: 10.1016/j. intimp.2014.06.032.

54. M. Bhaswant, H. Poudyal and L. Brown, Mechanisms of enhanced insulin secretion and sensitivity with n-3 unsaturated fatty acids, J. Nutr. Biochem. 26 (2015) 571-584; DOI: S0955-2863(15)00030-3.

55. T. D. Filippatos and M. S. Elisaf, Safety considerations with fenofibrate/simvastatin combination, Expert Opin. Drug Safety 14 (2015) 1481-1493; DOI: 10.1517/14740338.2015.1056778.

56. G. Derosa and P. Maffioli, Peroxisome proliferator-activated receptor-gamma (PPAR-gamma) agonists on glycemic control, lipid profile and cardiovascular risk, Curr. Mol. Pharmacol. 5 (2012) 272281; DOI: EPub-Abstract-CMP-51.

57. K. Wallenius, A. Kjellstedt, P. Thalén, L. Löfgren and N. D. Oakes, The PPAR $\alpha / \gamma$ agonist, tesaglitazar, improves insulin mediated switching of tissue glucose and free fatty acid utilization in vivo in the obese zucker rat, PPAR Res. 2013 (2013) Article ID 305347 (14 pages); DOI: 10.1155/2013/305347.

58. F. Gilardi, M. Giudici, N. Mitro, O. Maschi, U. Guerrini, G. Rando, A. Maggi, G. Cermenati, A. Laghezza, F. Loiodice, G. Pochetti, A. Lavecchia, D. Caruso, E. De Fabiani, K. Bamberg and M. Crestani, LT175 is a novel PPARalpha/gamma ligand with potent insulin-sensitizing effects and reduced adipogenic properties, J. Biol. Chem. 289 (2014) 6908-6920; DOI: 10.1074/jbc.M113.506394. 
59. L. S. Mackenzie and L. Lione, Harnessing the benefits of PPARbeta/delta agonists, Life Sci. 93 (2013) 963-967; DOI: 10.1016/j.lfs.2013.10.022.

60. H. J. Gim, H. Li, J. H. Jeong, S. J. Lee, M. K. Sung, M. Y. Song, B. H. Park, S. J. Oh, J. H. Ryu and R. Jeon, Design, synthesis, and biological evaluation of a series of alkoxy-3-indolylacetic acids as peroxisome proliferator-activated receptor $\gamma / \delta$ agonists, Bioorg. Med. Chem. 23 (2015) 3322-3336; DOI: 10.1016/j.bmc.2015.04.046.

61. G. Gupta, G. Krishna, D. K. Chellappan, K. S. Gubbiyappa, M. Candasamy and K. Dua, Protective effect of pioglitazone, a PPARgamma agonist against acetaminophen-induced hepatotoxicity in rats, Mol. Cell. Biochem. 393 (2014) 223-228; DOI: 10.1007/s11010-014-2064-9.

62. A. M. Lincoff, J. C. Tardif, G. G. Schwartz, S. J. Nicholls, L. Ryden, B. Neal, K. Malmberg, H. Wedel, J. B. Buse, R. R. Henry, A. Weichert, R. Cannata, A. Svensson, D. Volz and D. E. Grobbee, Effect of aleglitazar on cardiovascular outcomes after acute coronary syndrome in patients with type 2 diabetes mellitus: the AleCardio randomized clinical trial, JAMA 311 (2014) 1515-1525; DOI: 10.1001/jama.2014.3321.

63. X. C. Bao, Y. Q. Fang, P. You, S. Zhang and J. Ma, Protective role of peroxisome proliferator-activated receptor-beta/delta against pulmonary oxygen toxicity mediated through changes in NOS expression levels, Exp. Lung Res. 40 (2014) 105-116; DOI: 10.3109/01902148.2013.879497. 